Revista Tecné, Episteme y Didaxis: TED. Año 2014, Número Extraordinario. ISSN Impreso: 0121-3814, ISSN web: 2323-0126

Memorias, Sexto Congreso Internacional sobre Formación de Profesores de Ciencias. 08 al 10 de octubre de 2014, Bogotá

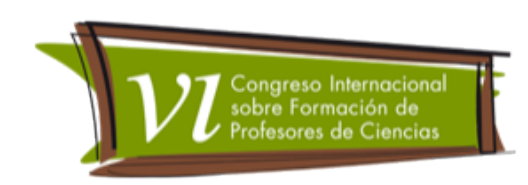

\title{
Possibilidades de experiências formativas no contexto da realização de um minicurso sobre o tema "água"1
}

Chagas Sobrinho, Luis Fernando', Chapani, Daisi Teresinha, Soares, Moisés Nascimento.

Cateoría 2. Trabalho de investigação

\section{Resumo}

Esse relato aborda as possibilidades apresentadas, para um licenciando de Ciências Biológicas, pelo planejamento, desenvolvimento e avaliação de um minicurso sobre o tema "água", ministrado a alunos de ensino fundamental de uma escola pública do município de Jequié, estado da Bahia. O minicurso ocorreu no contexto do estágio curricular supervisionado. Para análise das possibilidades oferecidas para a formação docente, utilizamos o conceito de experiência formativa, que se mostrou relevante para dar visibilidade à dimensão ética e estética na formação do futuro professor de ciências.

\section{Palavras chave}

Formação docente, atividades extracurriculares, Programa Novos Talentos

\section{Introdução}

Nesse momento histórico, de intensas transformações no mundo da cultura e do trabalho, novas exigências apresentam-se para a educação em ciências e, em consequência, para a formação de professores para ministrar disciplinas relacionadas às ciências da natureza. Assim, as licenciaturas dessa área têm buscado criar, recriar ou ampliar espaços formativos amparados por pressupostos mais críticos, estreitando as relações entre docência e pesquisa.

O curso de Ciências Biológicas da Universidade Estadual do Sudoeste da Bahia (UESB), campus de Jequié, apresenta disciplinas relativas às práticas pedagógicas desde o primeiro semestre, sendo que o estágio curricular supervisionado acontece na segunda metade do curso e envolve cinco disciplinas que buscam

\footnotetext{
1 Minicurso realizado com recursos do Programa Novos Talentos - Capes
} 
Revista Tecné, Episteme y Didaxis: TED. Año 2014, Número Extraordinario. ISSN Impreso: 0121-3814, ISSN web: 2323-0126

Memorias, Sexto Congreso Internacional sobre Formación de Profesores de Ciencias. 08 al 10 de octubre de 2014, Bogotá

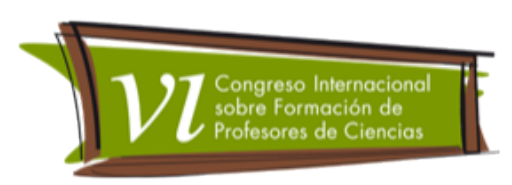

oferecer condições para que os discentes tenham uma experiência rica e significativa em seu processo formativo. Assim, os futuros professores envolvem-se em atividades de: reconhecimento da escola, participação na rotina escolar, realização de pesquisas e regência de classes. Além dessas ações, eles também planejam, desenvolvem e avaliam uma sequência didática envolvendo conteúdos de ciências naturais, que é ministrada a alunos de escolas públicas da cidade, em formato de minicurso.

Entre 2011 e 2013, esses minicursos foram desenvolvidos no contexto de um projeto institucional ligado ao Programa Novos Talentos - Capes, que tinha como principal objetivo a difusão do conhecimento científico e a reflexão sobre sua forma de produção. A participação de licenciandos nesse projeto visava a ampliação de seu repertório de conhecimentos e experiências sobre situações de ensino e aprendizagem em Ciências. Como atividade de estágio o minicurso que abordaremos neste trabalho esteve vinculado à disciplina "Metodologia e Prática do Ensino de Ciências Naturais", e foi orientado pelo professor da disciplina que também era o supervisor de estágio. Tal professor sugeriu que o plano de ensino destes minicurso estivesse embasado em algumas discussões recentes no campo do ensino-aprendizagem das ciências naturais, com especial atenção às diferentes dimensões dos conteúdos da disciplina escolar ciências, quais sejam: os conteúdos conceituais, procedimentais e os atitudinais (Campos; Nigro, 1999).

Dessa forma, foi desenvolvido o minicurso intitulado "Água: um bem precioso, porém finito", pelo primeiro autor deste relato e por mais uma licencianda. A escolha do tema deu-se por sua inquietação diante da realidade que se encontra a cidade de Jequié, no que se refere a seus rios polvídos, e pelo fato do tema possibilitar múltiplas formas de se trabalhar os conteúdos de ciências naturais.

\section{Desenvolvimento}

O minicurso foi realizado no campus da UESB e envolveu alunos do $6^{\circ}$ e $7^{\circ}$ ano do Ensino Fundamental, constituindo-se em cinco encontros com duração de 4 horas/aula, totalizando 20 horas/aula, e contou com a participação de 20 alunos com a faixa etária entre 12 e 14 anos de uma escola situada na periferia da cidade. O transporte para a locomoção dos alunos, o lanche que foi servido a eles e o material didático utilizado na intervenção foram custeados pelo Programa Novos Talentos - Capes. 
Revista Tecné, Episteme y Didaxis: TED. Año 2014, Número Extraordinario. ISSN Impreso: 0121-3814, ISSN web: 2323-0126

Memorias, Sexto Congreso Internacional sobre Formación de Profesores de Ciencias. 08 al 10 de octubre de 2014, Bogotá

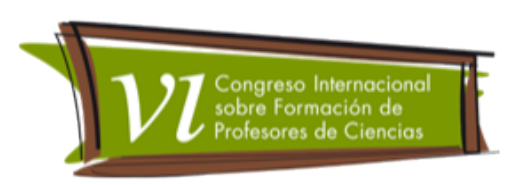

O objetivo geral do minicurso foi o de ajudar os alunos a ampliarem suas concepções sobre a importância da água para a origem e manutenção da vida, além de contribuir para o desenvolvimento do senso crítico dos mesmos, frente às ações insustentáveis do ponto de vista social, ecológico e econômico, relacionadas aos usos da água em nossa sociedade. A seguir faremos um relato reflexivo de cada um dos encontros.

No primeiro encontro tinha como objetivos levar os alunos a conhecerem as características da água e sua distribuição pelo planeta, levando-os a compreenderem que sem água não há vida conforme a conhecemos.

Para que esses objetivos fossem atingidos o minicurso iniciou-se com alguns questionamentos, a fim de gerar uma tempestade de ideias: O que é a água? Onde existe água? Qual a importância da água para as pessoas diariamente? E para as plantas e animais? Em seguida, houve sistematização do conteúdo por meio de uma aula expositiva-dialogada, na qual as respostas dos alunos foram utilizadas como fio condutor para apresentação de conceitos importantes sobre a água, tais como: estrutura química, formas de ocorrência, características importantes para a manutenção da vida, distribuição pelo planeta, etc. Num segundo momento, a turma foi dividida em grupos, onde se discutiu a letra da música "Água" (Paulo Tatit/Arnaldo Antunes), que retrata o ciclo hidrológico. Em seguida, foram exibidos e discutidos os vídeos "Ciclo da Água" e "Planeta Água". E por fim, num terceiro momento, os alunos foram para o laboratório de Limnologia da UESB, onde realizaram experimentos que demonstraram as seguintes características da água: solubilidade, densidade e tensão superficial.

Esse primeiro encontro foi muito satisfatório para todos os envolvidos, especialmente para o licenciando ministrante do minicurso, que considerou todas as atividades trabalhadas muito produtivas, uma vez que houve um retorno dos alunos, e ele pôde começar a construir uma relação professor-aluno em que foi possível realizar uma troca de conhecimentos ou seja, ele não era o único a agir durante a aula, todos participaram.

Porém, nesse dia também houve alguns conflitos, mais especificamente, um caso de bullyng, em que um grupo de meninas que agrediu verbalmente uma aluna, pois, essa destacava-se das demais por ser muito alta, o que a inibia de participar das atividades. Como era o primeiro contato do licenciando com o grupo e com este tipo de conflito, houve insegurança sobre como lidar com a questão. A 
Revista Tecné, Episteme y Didaxis: TED. Año 2014, Número Extraordinario. ISSN Impreso: 0121-3814, ISSN web: 2323-0126

Memorias, Sexto Congreso Internacional sobre Formación de Profesores de Ciencias. 08 al 10 de octubre de 2014, Bogotá

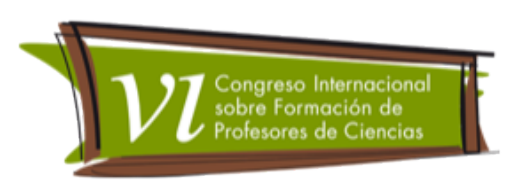

solução encontrada foi conversar primeiramente com a aluna agredida e depois com o grupo de garotas, que prometeram não insultá-la mais, e foi o que aconteceu ao longo de todos os encontros realizados. No entanto, considerou-se por bem dar ciência à escola do ocorrido.

O segundo encontro tinha como objetivo promover oportunidades para que os alunos problematizassem as consequências das ações antrópicas sobre a qualidade e distribuição da água no planeta.

Para tanto, iniciou-se o encontro com um trabalho em grupo que consistiu na leitura e interpretação de textos sobre o assunto e posterior elaboração de um cartaz que trouxesse, além dos problemas discutidos, também propostas de soluções. Num segundo momento, foi realizada uma aula de campo em uma represa situada nos arredores da cidade, onde os alunos puderam observar o local de captação da água que vai para a Estação de tratamento de água e também coletar uma amostra de água para posterior análise.

Essa experiência foi importante para o licenciando que não imaginava conseguir resultados tão bons com atividades relativamente simples, mas que instigaram os alunos a participarem ativamente na construção de seu conhecimento, principalmente com relação à atividade de campo e coleta de água para anal No Terceiro encontro, tinha-se como objetivo de discutir a ação antrópica sobre os corpos de água, seu uso sustentável e o grande problema das águas poluídas.

Para alcançar este objetivo foi pedido que os alunos representassem através de desenhos as consequências dos rios polvídos. Após este momento, os desenhos foram embaralhados e redistribuídos para cada aluno, que explicaram o que representava cada um. Em seguida, foi explicado o conceito de polvição, a partir de uma reportagem extraída de um jornal, cujo título era "Rio degradado sofre com o despejo de lixo", fez-se uma discussão do texto comparando com a realidade enfrentada pelo Rio de Contas, situado na cidade de Jequié. Por fim, foram exibidos dois vídeos "A ilha de lixo do Pacífico" e "Polvição dos Oceanos e Mares".

No Quarto encontro, tinha-se como objetivo promover a compreensão da importância da água tratada para a sua saúde e para alcançar este objetivo, foi realizada uma visita à Estação de Tratamento de Água, onde os alunos puderam observar todas as etapas do tratamento, e por fim, coletaram uma amostra da 
Revista Tecné, Episteme y Didaxis: TED. Año 2014, Número Extraordinario. ISSN Impreso: 0121-3814, ISSN web: 2323-0126

Memorias, Sexto Congreso Internacional sobre Formación de Profesores de Ciencias. 08 al 10 de octubre de 2014, Bogotá

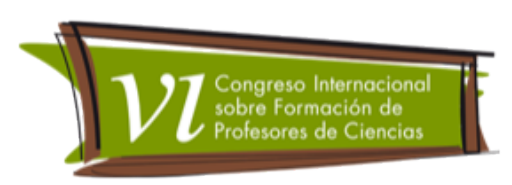

água pronta para o consumo. Após a visita à Estação, foram até o Rio de Contas, mais especificamente no local onde ocorre o despejo do Efluente da Estação de Tratamento de Esgoto, e observaram todo o ambiente, e coletaram uma amostra da água do rio.

Q Quinto encontro tinha como objetivo possibilitar aos alunos um contato com o mundo microscópico, bem como, a discussão sobre as doenças que podem ser adquiridas se a água não estiver em condições adequadas para o consumo humano. Para isso, foi realizada uma aula de laboratório, onde os alunos puderam observar ao microscópio a água que foi coletada nos diversos locais (de captação, tratamento e a que é despejada no rio após o tratamento de esgoto). Por fim, assistiram ao filme "Rango" que tratava sobre a escassez de água.

\section{Resultados e Conclusões}

Como atividade complementar a outras modalidades de estágio, a realização de minicursos por parte do licenciando em ciências biológicas mostrou-se bastante interessante, pois possibilitou o exercício da criatividade e da autonomia no planejamento, desenvolvimento e avaliação dessa atividade. Pensamos que tais conteúdos sejam centrais na estética da experiência como proposto por Adorno (2003); isto é, os professores exprimirem o diferenciado, autêntico e de luz própria como elemento estético do seu quefazer educativo.

Antes da realização do minicurso o licenciando estava bastante apreensivo, uma vez que seria o seu primeiro contato com os alunos e ele estava preocupado em não conseguir trabalhar os conteúdos de forma dinâmica e participativa. Porém, após este primeiro contato, ele ganhou confiança ao perceber que poderia realizar um bom trabalho, uma vez que a turma reagiu positivamente às propostas apresentadas. Mesmo o conflito ocorrido com o caso de bulling foi importante para que ele entrasse em contato com problemas e dificuldades comuns na escola e pudesse pensar em formas de lidar com tais situações. Neste particular a sensibilidade para lidar com dilemas morais tão próprios da profissão docente (Contreras, 2002), seja na relação aluno-aluno ou aluno-professor, constitui uma marca importância da experiência formativa (Maar, 2003).

O apoio do Projeto "Novos Talentos" foi importante para o desenvolvimento das atividades de laboratório, aula de campo, enfim, várias estratégias a fim de que 
Revista Tecné, Episteme y Didaxis: TED. Año 2014, Número Extraordinario. ISSN Impreso: 0121-3814, ISSN web: 2323-0126

Memorias, Sexto Congreso Internacional sobre Formación de Profesores de Ciencias. 08 al 10 de octubre de 2014, Bogotá

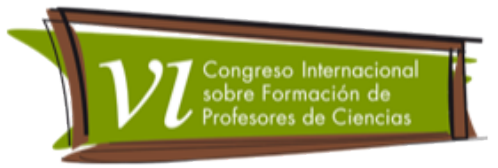

o futuro professor pudesse avaliar a pertinência de seu uso. Além disso, ele queria proporcionar aos alunos um contato com o microscópio e com outras atividades práticas, pois, eles não têm essa possibilidade na escola em que estudam, uma vez que a mesma não possui laboratório didático. Dessa maneira, ele percebeu que as práticas realizadas em laboratório e em campo, foram as que os alunos mais gostaram, pois tudo era novidade para eles. Além disso, foi importante trabalhar os temas relacionando-os com a realidade em que os alunos estavam inseridos, e isto foi muito bom, pois eles puderam expôr suas ideias ao longo das aulas.

Outro princípio importante que constitui a experiência formativa é a possibilidade de reflexão dos partícipes no calor da coletividade, tomando a teoria como elemento importante para problematização das práticas (Soares, 2012). Após a realização de alguns encontros do minicurso, os licenciandos tinham um espaço durante a aula da disciplina de estágio, em que podiam discutir juntamente com o professor suas experiências vividas. Neste sentido, eles puderam ao longo dos encontros, reelaborarem o plano de ensino sempre que fosse preciso, com a ajuda dos colegas e do professor. E como a proposta deste último era que os estagiários desenvolvessem nos alunos um posicionamento crítico, e levássemos sempre em conta o histórico de vida de cada um deles, foi trabalhado os princípios teóricos da proposta, que englobava a retomada contínua das discussões dos conteúdos conceituais, procedimentais e atitudinais como balizadoras das ações.

O licenciando passou a reconhecer que foi neste espaço de discussão que ele pôde construir e reconstruir sua personalidade de professor, conseguindo ali reestruturar suas estratégias didáticas, visando desenvolver o posicionamento crítico dos seus alunos. Considera que teve dificuldades em como questioná-los afim de que todos eles participassem das discussões, porém, ao expor estas dificuldades durante a disciplina obteve muitas contribuições e reconhece que aprendeu muito com seus colegas de turma e com o referido professor, legitimando tais espaços como importantes na construção da sua identidade docente.

Assim sendo, pensamos que a proposta contribuiu para que o licenciando ampliasse seu repertório de conhecimentos e práticas, que poderá ser mobilizado quando estiver no exercício da docência. Entre tais conhecimentos e práticas destacamos: uso de metodologias diversificadas para o ensino de ciências; 
Revista Tecné, Episteme y Didaxis: TED. Año 2014, Número Extraordinario. ISSN Impreso: 0121-3814, ISSN web: 2323-0126

Memorias, Sexto Congreso Internacional sobre Formación de Profesores de Ciencias. 08 al 10 de octubre de 2014, Bogotá

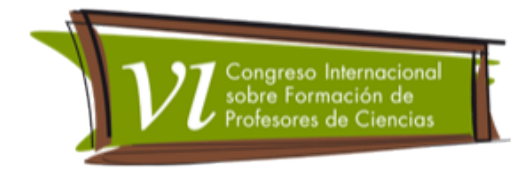

reflexões sobre o contexto de vida dos alunos; conhecimento de algumas dificuldades comuns aos professores de educação básica que remetem ao dilema de sua obrigação moral como profissional da educação ao lidar com incertezas, medos e conflitos e, por fim, uma reflexão sobre os elementos da prática pedagógica, como a importância do re-planejar de forma coletiva e da relação teoria e prática. Tal repertório parece evidenciar as possibilidades do constructo experiência formativa em caracterizar elementos da dimensão ética e estética implicados nas práticas educativas na formação do futuro professor de ciências.

\section{Agradecimentos}

Agradecemos ao professor Marcos Lopes de Souza, que supervisou o estágio na forma de minicurso, e à discente Zuleide Oliveira Aguiar, que participou de sua realização.

\section{Referências Bibliográficas}

Adorno, T. W. (2003). Educação e Emancipação. Rio de Janeiro: Paz e Terra.

Campos, M. C. C.; Nigro, R. G (1999). Didática de Ciências: o ensinoaprendizagem como investigação. São Paulo: Fłd.

Contreras, J (2002). A autonomia do professor. São Paulo: Cortez.

Soares, M. N (2012). O estágio curricular supervisionado na licenciatura em ciências biológicas e busca pela experiência formativa: aproximações e desafios. Faculdade de Ciências, Universidade Estadual Paulista, Bauru. 